\title{
Production Internet - Functional Perspective
}

\author{
Stanisław Strzelczak \\ Warsaw University of Technology, Faculty of Production Engineering, Warsaw, Poland \\ s.strzelczak@wip.pw.edu.pl
}

\begin{abstract}
Production Internet as an eco-systemic Web-based infrastructure goes beyond the traditional setups of industrial cooperation, as well as existing peer-to-peer services for economic exchange, like e-tailing, e-sharing or crowdfunding. This paper investigates the feasibly functional arrangements of Production Internet. Throughout reflection on the state-of-art, supplemented by a foresight research, the needs, requirements and benefits are identified then composed into functional setting, which was validated using a prototype implementation. The discussed conceptualization is expected to improve operational effectiveness, efficiency of resources, and reduce transaction costs.
\end{abstract}

Keywords: Production Internet, Collaborative Networks, Cloud manufacturing, Production Ecosystems, Supply Chains, Smart Manufacturing, Web-services.

\section{Introduction}

The industries are growingly exposed to openness and networking. The major drivers of this megatrend are globalization and ICT developments. The first eco-systems built upon Internet capabilities like Alibaba or Facebook, exhibit strong and global impacts in their domain of operation. The key Web-based eco-systemic developments are coined together as the Seven Internets [12]. Some of them, like the Logistics (Physical) Internet [7] and Production Internet [12] are still rather concepts, than a reality. The latter one, which is expected to provide a new economic and organizational momentum to the globally networked industries, is investigated in this paper.

Production Internet goes beyond the peer-to-peer based Web-services for economic exchange: e-tailing, crowd-funding, e-sharing, etc. The breaking innovation is by support of structured workflows of products/services, and also by automated matching of demands and resources. The rise of Production Internet is conditioned by particular technologies. The most vital are Web services and semantic technologies [2]. The other important are: multi-agent systems, smart technologies and CPS, cloud computing, and Service Oriented Architectures (SOA). By alignment of capacities and demands of collaborating parties, Production Internet departs from the existing forms of buyer-supplier relationships, like markets, supply chains or partnerships.

The focus of this paper is on functional development of Production Internet, while technology aspect is treated secondarily. The core functions of Production Internet are built around qualitative and quantitative fits of products and services with resources, along demand flows. 
The paper is organized as follows. The next section reviews the state-of-art: drivers of industrial networking, developments of ICT, and Internet solutions which herald the Production Internet. Section 3 introduces the foresight research and presents key findings. Section 4 discusses the most promising uses and users, and the expected benefits. Section 5 projects functional specification for the beginning and prototype developments. Section 6 reports the prototype implementation, which was primarily intended to validate the concept, and enable future experimental research. Section 7 summarizes the paper and reflects on further research and development.

\section{State-of-Art}

This section reflects on existing theories of industrial networking, and available ICT aids. This way the starting point for Production Internet development can be learned.

The strategic importance of ICT to support industrial networking is determined by possible benefits, mostly in terms of competitive advantage and economic performance. The industrial networking follows a variety of archetypes, ranging from traditional market supply to novel forms of virtual collaboration. With this regard the theoretical basis for adoption of ICT support can be viewed by the lenses of the five established theories. The resource based view centers on the offering of capacities and capabilities as the source of competitive advantage [1]. In this view ICT is expected to support performance of resources. The transaction costs theory focuses on governance structures of economic exchange [14]. Herein ICT can be viewed as a mean to reduce transaction costs of searching contractors, bidding, etc. The relational view seeks competitive advantage in inter-organizational relationships [3]. Therefore the strategic role of ICT can be seen as facilitator to relationships management. The dynamic view focuses on organizational capabilities to rapidly and smoothly adapt, reconfigure, integrate and extend resources and abilities, in response to changing requirements and needs [13]. Similarly, ICT can be viewed as enabler and facilitator to dynamic capabilities. The resource dependence theory considers uncertainty due to utilization of resources of other firms [8]. Accordingly the role of ICT is to aid ability of an organization to control or limit the dependence on others resources. The concept of Production Internet apparently responds to all established theories of industrial networking.

The existing ICT solutions and technologies that can support industrial networking, which typically take the user-company perspective, are represented by variety of systems and technologies [4, 5, 9, 11]: ERP1, ERP2, EAI, ERP adapters, SCM, DRP, CRM, WMS, TMS, ECR, CPFR, EDI and I-EDI, mobile \& tracking technologies (MCRM, RFID, PDA et al.), Web services, Semantic Web, grid computing, cloud manufacturing, cloud-ERP, knowledge-based systems, ontologies, intelligent agents. If the existing systemic solutions offer any capacity to consider structures of products or services, it is by proprietary systems used within a rigid setting of cooperation. Centrally maintained data structures are used in such cases to represent products or services [10]. Otherwise the coordination is operated on transaction basis: B2B, B2C, $\mathrm{O} 2 \mathrm{O}$ etc. The existing systems typically use classic triggering mechanisms to coordinate inter-organizational operations, like replenishment or pull flows. The offerings of 
products, services and resources to external parties are typically given as specified items (catalogues). Qualitative characterization with this regard is not yet exploited. Although the recent concept of cloud manufacturing hypothetically provides a significant potential to support the development of Production Internet, it still remains rather a research topic discussed at high level, and mostly from architectural and technology point of view [4]. However some Web services emerging in China and USA clearly anticipate the rise of Production Internet and can be viewed as its heralds. All of them represent the megatrend coined as sharing or access economy, which concerns such economic arrangements, in which the participants open and mutualize the access to resources, products and services, rather than exploit advantages of ownership. The representative examples are: Alibaba/Taobao as ecosystem for clients, manufactures, sellers and forwarders; CreditEase as platform for peer-to-peer lending and microfinance; Groupon as demand bulking service; Covisint as auctioning platform to purchase standard products; Zuora as demand subscription service; NetSuite OneWorld as cloud service for multi-company management of resources; Kickstarter crowdfunding platform as demand, supplies and funds amalgamation service; Cybernauts as platform to support start-ups, alliances, joint ventures, and similar, to integrate the entrepreneurs and venture micro-capital. Although the listed solutions exhibit a reach variety of networking services, they do not go beyond the limits of peer economy, and follow the integration patterns of online market places, or proprietary platforms. Nevertheless, they clearly indicate the probable directions of functional development.

\section{Foresight Research}

This section reviews the foresight research of Production Internet. The key aim is to identify the most probably functional developments, considering the needs and requirements of potential users. The expert panel involved: Web-services providers (Taobao, Cybernauts, Haozhuanye, Alo7), technology providers (Huawei, SAP), ICT venture capital (KnowledgeHub), consultancy (Accenture), and professional societies (Crowdfunding World Championship Council). The semi-structured interviewing and brainstorming was run in a face-to-face mode, mostly virtually. A set of questions was provided in advance then used to lead interviews, supplemented by other direct, indirect, and ad hoc questions. Following topics have been centered on: (i) new forms of inter-organizational collaboration in terms of: services/processes; structures; coordination principles; patterns of demand, service, and resource offerings; (ii) heterarchical, distributed and herd control of operations; (iii) new functionalities; (iv) knowledge and cognitive supports, semantic networking, knowledge management; (v) trust and credibility management; (vi) most promising patterns of deployment; (vii) benefits. All interviews were documented, and in most cases recorded. The suggestions of panelists were just plainly compiled, while opinions were not weighted.

The leading findings from the research can be condensed as follows:

1. Production Internet should firstly focus on manufacturing, stock keeping, forwarding and selling activities, as well as related coordination. These should be gradually supplemented by a variety of support services: (1) trust, reliability, and credibility 
management; (2) bidding; searching, discovery, and matching of various offerings and demands, both in qualitative and quantitative way, and considering spatiotemporal aspects; (3) tracking demand, work and material flows, payments; (5) management of legal responsibility; (6) confidentiality management; (7) funding;

2. Final clients, manufacturers, and forwarders are recognized as the key actors along the beginning developments of Production Internet;

3. The bills of materials/processes based coordination, and using relational databases is assessed as ineffective in large scale environments by most experts; novel forms of demand should be considered, especially by going beyond the 'due date-due quantity' concept, and avoiding schedules based coordination;

4. Distributed and heterarchical modes of coordination should be further explored;

5. Robotized decision making, using cognitive abilities, should be investigated to overcome the shortcomings of human decision making (e.g. due to the asymmetric perception of risk, herd behavior, learning and forgetting asymmetries); other supports, like business intelligence, Big Data, could be also considered in the future;

6. Recognizing regional and overall characteristics of ecosystems, like states or phase transitions (e.g. in reference to changing loads or variability characteristics), to facilitate and modify the ongoing coordination of flows, should be investigated;

7. Interacting with the existing legacy/local systems should be considered.

The suggestions of experts can be also synthesized into an evolutionary pattern indicating the main directions for functional development of Production Internet (Fig. 1).

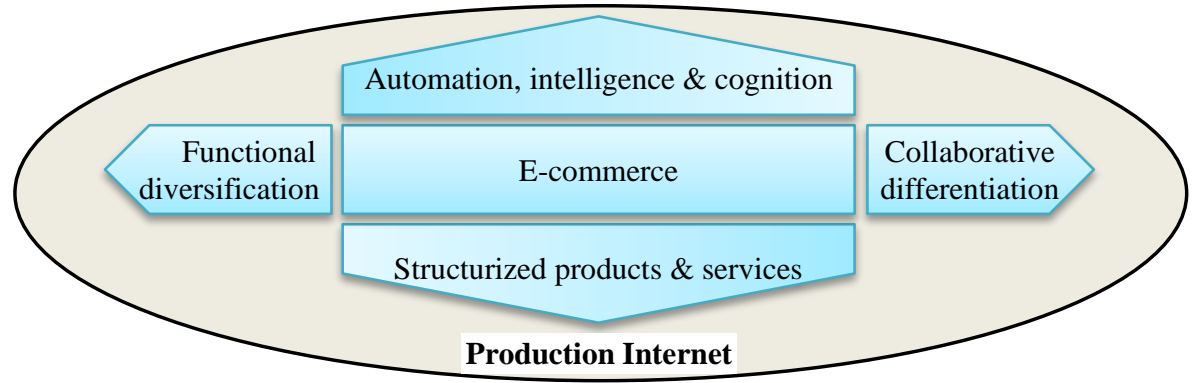

Fig. 1. Evolution towards Production Internet - main directions

Experts suggest E-commerce ecosystems (Alibaba/Aliexpress) as a starting basis to develop the Production Internet. The prior breaking innovation should be consideration of products and services as structurized items. This grounding development shall be followed in a twofold way by functional diversification, i.e. by adding consecutive functions (as listed before), and collaborative differentiation, i.e. by adding new actors and forms of networking. The crowning of Production Internet will be throughout progressive enrichment with automation and artificial intelligence, including the autonomous cognition. Some experts suggest that bio- or eco-mimicking intelligence to maintain homeostasis of production ecosystems could be innovated with this regard.

Other results of this research are also referred and exploited in the further sections. 


\section{Dissemination and Benefits}

The research introduced in the preceding section has also identified a range of success factors for the extensive dissemination of Production Internet. It was done by projecting the most probable uses and users, in terms of their characteristics, needs, requirements, and expected benefits. The factors for successful dissemination of Production Internet, as suggested by experts, are listed in Table 1. Although some of them are not strictly independent, they were weighted separately by $1 \div 10$ scale (lowest to highest).

Table 1. Key factors for successful dissemination of Production Internet

\begin{tabular}{|c|l|c|}
\hline No. & \multicolumn{1}{|c|}{ Factor } & Av.weight \\
\hline 1 & User is a small party (SME) & 10 \\
\hline 2 & Very low to medium repetitiveness \& volume of flows & 9,5 \\
\hline 3 & Low investment to enter transaction or collaboration (equipment, etc.) & 9 \\
\hline 4 & High variability of flows & 9 \\
\hline 5 & Sourcing effort high to medium & 9 \\
\hline 6 & Many sourcing options & 8,5 \\
\hline 7 & Customized products (assembly- to engineer-to order) & 7,5 \\
\hline 8 & No requirements for certifications & 7,5 \\
\hline 9 & Low or moderate complexity of flows & 7,5 \\
\hline 10 & In-house or outsourced design & 6,5 \\
\hline
\end{tabular}

From the above view we can conclude about the most probably uses and users of Production Internet. It should be primarily attractive to such SMEs, who offer customized products (ATO to ETO) at low volumes, rather in a non-repetitive mode, and for whom the sourcing effort and transaction costs are important. Other factors of susceptibility are variability, low or moderate complexity flows, no requirements for certifications, and no need for shared design.

The research panel has also identified the most important and distinctive advantages, which can result from using the Production Internet:

- Increased visibility of offerings; hence improved efficiency of owned resources;

- Improved operational performance (lead times, inventory turnover, productivity, flexibility); increased capital turnover; overcame economy of scale;

- Easy and fast matching of offerings; hence, reduced transaction costs;

- Reduced and optimized dependence on resources of other firms;

- More synergies due to exploitation of complementary and distinctive resources;

- Improved changeability and reduced need for changeability.

Apart of the benefits to users, which interestingly correspond with all theories of industrial networking discussed in section 2, the overall impacts on economy, society and environment, were also appreciated by the panel, like e.g.: improved efficiency of the whole economy; increased capital turnover; less wasteful economy; tamed powers of spatial concentration of economic activities due to improved opportunities for localized and distributed economic activities; increased welfare; more inclusive and sustainable economy; improved eco-friendliness (reduced emissions, pollution, etc.). 
The above reviewed findings made by the research panel provide a sound argument in favor of dissemination of Production Internet, and suggest the most prospective uses and users. As the technological barrier in terms of ICT does not actually exist, it is only a matter of time before arise of the first Production Internet platform.

\section{$5 \quad$ Functional Specification for Prototyping}

This section lists the functionalities that are most likely offered by first implementations of Production Internet, to be included in the prototype development. They were directly concluded or detailed from the before reported results of foresight, as well as from the functional analysis of only existing eco-systemic platform for E-commerce, i.e. Aliexpress. They are:

1. Offering and processing of structured demand (products/services);

2. Offering of resources (processing, warehousing, forwarding);

3. Credibility assessment and conditioning (including reliability and trust);

4. Qualitative, quantitative and spatiotemporal matching of demands and provisions;

5. Demand (orders, subscriptions, schedules) and orders processing; orders tracking;

6. Operational coordination of material, work and information flows (based firstly on ordering and pull flow principles, VMI, and to limited extend on pull flows);

7. Product and process information management;

8. Discounting, bidding, auctioning;

9. Claims and returns management;

10. Payments management.

It was presumed, following the opinions of research panel, that the first users will be final clients and the bidders of products, resources or manufacturing services.

\section{Prototype Development}

This section reports a prototype development of Production Internet. It is mainly aimed to enable experimental research and educational use. Another purpose is to validate the concept of Production Internet.

The development is based on multi-agent systems [6] and ontology engineering [11]. The multi-agent environment provides capacity for mimicking Web services and Web-based interactions [6]. Additionally it provides a setting for the Service-Oriented Architectures and cloud-based infrastructures [6]. It was also considered as the initial mean to automate coordination activities. The prototype implementation was made using the GAIA based conceptualization, and JADE, WADE and WOLF toolkits.

For the prototyping purposes distributed ontologies were assumed as the only mean to process data and knowledge [11]. The ontology for discussed development was elaborated by adaption of the TRANSFORMERS ontology for manufacturing and logistics, which was elaborated before at Warsaw University of Technology [11]. All interacting agents (robots) are equipped with own operational ontologies. 
A layered architecture was assumed for the prototype development. The main function of the bottom layer, i.e. 'transaction layer', is to process offerings. Two types of robots are employed herein: (i) 'propositioning robots' handle the offerings; (ii) 'transaction supervisory robots' manage all services related to the use of resources, fulfillment of internal orders, receiving, and forwarding. This layer interfaces users, resources, as well as real processes.

The upper layer, i.e. the 'brokerage \& coordination layer' incorporates the whole collectivity of robots that align demands and offerings. Their key roles consist in spatiotemporal matching of products, resources, services and demands. The robots compose structures of products, and then processes to enable planning and operation of indispensable services. The transformational approach is applied to explode and aggregate demands, then processes, following the approach of transformational paradigm [6]. This way the whole spatiotemporal mereotopology of demands, processes, and resources can be operated in a coherent and homogenous manner. The 'brokering robots' match demands, resources and services, while the cohort of 'balancing robots' leverage the traffic of flows, considering utilization and synchronization aspects.

As yet only two above layers have been implemented. The 'homeostasis layer' takes an aggregate view of operations, and focuses on the overall balance of loads and flows, i.e. as viewed within the whole ecosystem. It concerns blockings and jams that can be brought about by temporal overloads of manufacturing or forwarding capacities, or alternatively by delimited material and resource supplies. The products and resources are roughly cut into qualitative and spatial categories to anticipate the temporal overloads and jams. Alternative streaming of flows can be then advised by 'streaming robots' to the balancing robots. The role of this layer analogizes the aggregate planning, and also follows the idea of adaptive control.

The top layer, i.e. the 'layer of evolution' considers the self-adoption of Production Internet following the concept of autonomous cognition. New behavioral patterns can be self-learned with regard to the observed changes, e.g. in terms of variability, mix of services, and similar. The change can be implemented by embedding new behavioral rules into the knowledge of robots operating in the lower layers. Although at the first glance this kind of capabilities may be viewed as futuristic, actually the available cognitive technologies enable its implementations, at least in some interesting areas, like e.g. the widespreading of newly learned rules of allocating demands and services into the knowledge bases (ontologies) of balancing and streaming robots.

As yet the initial prototype development employs a limited scope of functionalities, namely the first seven of listed in section 6 . It does not pay attention to the scalability. This kind of approach can be justified by the focus of the first development on functional aspects, and with this regard - on discovery of particular issues that can be faced in the future along the further development of the Production Internet.

\section{$7 \quad$ Summary and Future Work}

This paper investigates the possible functional settings of Production Internet. Throughout reflection on the state-of-art, supplemented by a foresight research, the 
needs and benefits were identified then composed into functional conceptualization, which was validated using a prototype development. The eco-systemic solutions of Production Internet should significantly limit the shortcomings of existing economical institutions, especially by improved operational efficiency, increased sharing and better utilization of resources, improved transaction costs economics, and finally by improved economic performance of economic exchange.

The future research should explore full scope of functionalities and networking. The deployment of cognitive abilities could be another important extension. Other aspects, like scalability, interoperability, also provide challenges to the further work.

\section{References}

1. Barney, J.: Firm resources and the sustained competitive advantage. Journal of Management 17(1), pp. 99-120 (1991).

2. Berners-Lee, T., Hendler, T., Lassila, O.: The Semantic Web. Scientific American, 2001/V, pp. 34-43 (2001).

3. Dyer, J.H., Singh, H.: The relational view: cooperative strategy and sources of interorganizational competitive advantage. Academy of Management Review 23(4), 660-679 (1998).

4. He, W., Xu, L.: A state-of-the-art survey of cloud manufacturing. International Journal of Computer Integrated Manufacturing 28(3), pp. 239-250 (2015).

5. Holma, H., Salo, J.: Improving management of supply chains by information technology. In: Waters, D., Rinsler, S.: Global Logistics - New Directions in Supply Chain Management. Kogan Page, pp. 227-243 (2015).

6. Leitão, P., Karnouskos, S. (eds.): Industrial Agents: Emerging Applications of Software Agents in Industry. Elsevier, pp. 153-170 (2015).

7. Montreuil, B.: Physical Internet Manifesto. http://www.physicalinternetinitiative.org/ Physical\%20Internet\%20Manifesto_ENG_Version\%201.11.1\%202012-11-28[1], last accessed 2015/04/01.

8. Pfeffer, J., Salancik, G.: External Control of Organizations: A resource dependence perspective. Harper and Row, New York (1978).

9. Shi, X., Chan, S.: Information systems and information technologies for supply chain management. In: Waters, D., Rinsler, S.: Global Logistics - New Directions in Supply Chain Management. Kogan Page, pp. 210-226 (2015).

10. Strzelczak, S., Berka, A.: Contribution of the Theory of Parallel Computation to the Management of Distributed Manufacturing Systems. In: Bin, H., McGeough, J.A., Wu, H., (eds.), Computer-Aided Production Engineering, pp. 29-42. PEP Ltd., London (2001).

11. Strzelczak, S.: Implementing Ontologies in Manufacturing and Logistics - From Theoretical Fundamentals to Prospects. In: Strzelczak, S., Balda, P., Garetti, M., Lobov, A. (eds.), Open Knowledge Driven Manufacturing and Logistics - the eScop Approach, pp. 111-213. OWPW, Warsaw (2015).

12. Strzelczak, S.: Towards Intelligent and Sustainable Economy - From Incas, through eScop, to the Seven Internets. In: Proceedings of the International Conference on "Technology • Intelligence • Future”, pp. 324-336. Boao Edu Forum Asia, Chengdu (P.R.China), (2015).

13. Teece, D.J., Pisano, G., Shuen, A.: Dynamic capabilities and strategic management, Strategic Management Journal, 18(7), pp. 509-533 (1997).

14. Williamson, O.E.: Transaction-Cost Economics: The Governance of Contractual Relations. Journal of Law and Economics 22(2), pp. 233-261 (1979). 